\title{
Antioxidant and Antibacterial Activities for Several Phenolic Compounds in Selected Personal Care Products
}

\author{
MOHAMMED AKKBIK, ZAINI BIN ASSIM* \& FASIHUDDIN BADRUDDIN AHMAD \\ Department of Chemistry, Faculty of Resource Science \& Technology, \\ Universiti Malaysia Sarawak, 94300 Kota Samarahan, Sarawak, Malaysia.
}

\begin{abstract}
The radical scavenging activity of phenolic compounds such as butylated hydroxyanisole (BHA) and butylated hydroxytoluene (BHT) as antioxidants, and octyl methylcinnamat (OMC) as UVB-filter in selected personal care products such as sunscreen cream, milk lotion, hair oil and hair gel were evaluated. 2,2-diphenyl-1-picrylhydrazyl (DPPH) radical was used as reagent and antioxidant activity expressed as decrease in the percentage of DPPH. The antibacterial activities of BHA, BHT, OMC and mixture were assessed using two techniques of agar plate diffusion method. The mixture of BHA, BHT and OMC showed the highest percentage of $\mathrm{DPPH}^{\circ}$ inhibition $(95.2 \%)$, followed by BHA $(94.8 \%)$, BHT $(93.9 \%)$ and OMC $(9.0 \%)$. DPPH inhibition for crude extracts of selected personal care products were evaluated. The percentage of DPPH inhibition for sunscreen cream, milk lotion, hair gel and hair oil were $15.3 \%, 23.5 \%, 7.7 \%$ and $12.7 \%$, respectively. While $\mathrm{IC}_{50}$ of BHA, BHT and mixture were observed at 29.83, 44.16, $32.51 \mathrm{mg} / \mathrm{L}$, respectively. The MIC values for BHA, BHT, OMC and mixture against $E$. coli using paper-disk diffusion technique were 1.5, 15, 200, $1.5 \mu \mathrm{g} /$ disk, respectively. While, the MIC values obtained using hole-punch technique were 100, 200, not active, $70 \mu \mathrm{g}$ hole for BHA, BHT, OMC and mixture, respectively. In addition, the MIC values obtained by paper-disk diffusion technique for BHA, BHT, OMC, and mixture against $S$. aureus were 15, 70, not active, $10 \mu \mathrm{g} /$ disk respectively. On the other hand, MIC values obtained using hole-punch technique were 70 , 200, not active, $60 \mu \mathrm{g}$ /hole for BHA, BHT, OMC and mixture, respectively.
\end{abstract}

Keywords: Phenolic compounds, personal care products, radical scavenging, $\mathrm{DPPH}, \mathrm{IC}_{50}$

\section{INTRODUCTION}

Butylated hydroxyanisole (BHA) and butylated hydroxytoluene (BHT) behave as phenolic antioxidants due to the reactivity of the hydroxyl substituent on the aromatic ring (Peschel et al. 2006). The antioxidant activity of BHA and BHT is related to scavenging free radicals, chelating transition metals involved in free radical production (capable of catalyzing oxidation) and inhibiting the enzymes participating in free-radical generation (Apostolova et al. 2008). No evidence to prove the antioxidant and antibacterial activities of octyl methylcinnamat (OMC). However, p-methoxycinnamic acid (OMC is ester of p-methoxycinnamic acid) had capability to scavenging free radicals and inhibit growth of grampositive and gram-negative bacteria (Lee et al. 2006; Nakazono et al. 2006).

Both BHA and BHT have capability to inhibit the growth of gram-positive and gram-negative bacteria. (Chew et al. 1985; Post \& Davidson 1986;

*Corresponding author: zaini@frst.unimas.my
Collins \& Charles 1987; Tseng \& Tseng 1995; 2009). The inhibitory power of BHA, BHT against lipid composition of bacterial species is due to disruption of the cytoplasmic membrane of bacteria cells since BHA and BHT are very soluble in lipids (Post \& Davidson 1986; Simonetti et al. 2003; Klich et al. 2009; Romano et al. 2009).

The DPPH method has been widely used to evaluate antioxidant activity in plant extracts and biological systems with varying results (Thaiponga et al. 2006). This method is simple and quick due to the simplicity of the equipment required. Several methods have been used to evaluate the antibacterial activity of phenolic compounds such as agar plate diffusion, agar dilution and broth microdilution methods (Osman et al. 2009; Singh et al. 2008; Gaudreau et al. 2008; Chryssanthou \& Cuenca-Estrella 2006). This paper reports the evaluation of the antioxidant and antibacterial activities of BHA, BHT, OMC, mixture and extract from selected personal care products using DPPH and agar plate diffusion method. $\mathrm{IC}_{50}$ and $\mathrm{MIC}$ for BHA, BHT, OMC and mixture are also reported. 


\section{MATERIALS \& METHODS}

\section{Chemical Reagent and Standard Solution}

All chemical reagents used for extraction and dilution were analytical grade of Merck (Darmstadt, Germany). The reagents include n-hexane, methanol and acetonitrile. DPPH $^{\circ}$ (2,2-diphenyl-1picrylhydrazyl) radical reagent was purchased from Sigma, USA. Standards of BHA $(96 \%)$, BHT $(99.8 \%)$ and OMC (98\%) were purchased from ACROS-ORGANICS (New Jersey, USA). A 5000 $\mathrm{mg} / \mathrm{L}$ stock solution for each BHA, BHT and OMC in methanol was prepared by weighing equivalent accurately $1250 \mathrm{mg}$ of BHA BHT, OMC. The flask was then shaken until a homogenous and clear solution formed and diluted with methanol to total volume of $250 \mathrm{~mL}$. The stock solution was covered with aluminum foil and stored in a freezer $\left(4^{\circ} \mathrm{C}\right)$ and away from light for a maximum of one month.

\section{Extraction of Phenolic Compounds from Personal Care Samples}

Extraction of BHA, BHT and OMC from personal care samples was performed using a reflux method according to procedure outlined by Gulcin et al. (2009) with a slight modification. Briefly, 0.3 to $2 \mathrm{~g}$ personal care samples were accurately weighed in the $100 \mathrm{~mL}$ capacity round bottom flask. Prior to extraction, lipids, fatty acids and volatile oils were removed from the sample by addition of $25 \mathrm{~mL}$ hexane and $25 \mathrm{~mL}$ acetonitrile. The sample was then extracted under reflux for 30 minutes at $70^{\circ} \mathrm{C}$. The crude extract was transferred to separatory funnel and two layers were formed. The n-hexane phase was repartitioned for three times using $10 \mathrm{~mL}$ of acetonitrile and shaked vigorously. The n-hexane phase was removed and acetonitrile phase was collected. The extract was then concentrated on a vacuum rotary evaporator. The residue was redissolved with $5 \mathrm{~mL}$ of methanol and transferred into a $10 \mathrm{~mL}$ volumetric flask after filtration. Finally, it was then diluted to $10 \mathrm{~mL}$ with methanol.

\section{Determination of Antioxidant Activity}

The antioxidant activity of crude extracts from selected personal care samples was determined using the procedure developed by Brand-Williams et al. (1995) and slightly modified by Mandal et al. (2009). Exactly $0.4 \mathrm{~mL}$ of extract was mixed with 4 $\mathrm{mL}$ of $0.1 \mathrm{mM}$ DPPH and shaked 15 seconds. The mixture was left at room temperature for 30 minutes in dark place. The absorbance of the sample was measured by UV-Visible spectrophotometer model Lambda 25 at $517 \mathrm{~nm}$ for every 5 minutes until 30 minutes. A control was a mixture of $0.4 \mathrm{~mL}$ of distilled water and $4 \mathrm{~mL}$ of $0.1 \mathrm{mM}$ DPPH: Both BHA and BHT were selected as positive control. The radical scavenging activity was calculated as the percentage of $\mathrm{DPPH}^{*}$ discoloration using the equation below (Katalinic et al. 2006):

$$
\begin{aligned}
& \% \mathrm{DPPH} \text { radical scavenging }=\left[1-\left(\mathrm{A}_{517} \mathrm{~nm}\right.\right. \\
& \text { sample } \left.\left./ \mathrm{A}_{517} \mathrm{~nm} \text { control}\right)\right] \times 100 \\
& \text { where, } \mathrm{A}_{517} \mathrm{~nm} \text { sample is sample absorbance } \\
& \text { at } 517 \mathrm{~nm} \text {, } \\
& \mathrm{A}_{517} \mathrm{~nm} \text { control is } \mathrm{DPPH} \text { absorbance without } \\
& \text { sample at } 517 \mathrm{~nm} \text {. }
\end{aligned}
$$

\section{Determination of Antibacterial activity}

Seven standard solutions with concentrations of $0.06,0.4,0.6,2.4,4.8,8$ and $16 \mathrm{mg} / \mathrm{mL}$ for each BHA, BHT, OMC and mixture were prepared by mixing methanol with sterile nutrient broth (10:90, $\mathrm{v} / \mathrm{v}$ ) (Romano et al. 2009). The $\mathrm{pH}$ of the nutrient broth was readjusted to 5.5 by the addition of small volume of $\mathrm{HCl}$ (Collins \& Charles 1987). The antibacterial activity of crude extract for selected personal care samples (sunscreen cream, milk lotion, hair gel and hair oil) were monitored using the procedure described by Romano et al. (2009). Briefly, the residue was redissolved with $10 \mathrm{~mL}$ mixture of methanol and sterile nutrient broth $(10: 90, \mathrm{v} / \mathrm{v})$ and transferred into a $10 \mathrm{~mL}$ volumetric flask after filtration. This mixture was then diluted to $10 \mathrm{~mL}$ with mixture of methanol and sterile nutrient broth $(10: 90, \mathrm{v} / \mathrm{v})$.

The antibacterial activity for BHA, BHT, OMC, mixture and extract of selected personal care samples against $S$. aureus (ATCC 29213) and E. coli (ATCC 25922) were evaluated by using two techniques of agar plate diffusion method. In the paper-disk diffusion technique, four sterile paper disks $(4 \times 6 \mathrm{~mm}$, Whatman) were placed on the surface of solidify seeded agar plates by using sterile forceps (Abdoul-Latif et al. 2010). Whereas in holepunch diffusion technique, four holes $(4 \times 8 \mathrm{~mm}, 3$ $\mathrm{mm}$ depth) were punched with sterile cork borer and placed on the surface of solidify seeded agar plates (Osman et al. 2009). Sterile paper disks or holes were then impregnated with $25 \mu \mathrm{L}$ of extract with seven different concentrations of phenolic compound standards and allowed to dried under aseptic conditions at $28^{\circ} \mathrm{C}$ by using Bunsen burner. The inoculated agar plates were incubated inverted at $37^{\circ} \mathrm{C} \pm 0.5$ for 24 hours. After the incubation period, the diameter of inhibition zone of each hole or disk was measured in $\mathrm{mm}$ by using ruler with 
accuracy of $0.5 \mathrm{~mm}$. The minimum inhibition concentration (MIC) is defined as the lowest concentrations of an antimicrobial agent which will give the lowest visible zone (Singh et al. 2008).

\section{RESULTS \& DISCUSSION}

\section{Antioxidant Activity}

The DPPH scavenging activities of phenolic compounds were expressed as the percentage of DPPH decrease (Ozgen et al. 2006). A mixture sample containing of BHA, BHT and OMC showed the highest $\mathrm{DPPH}^{*}$ inhibition activity with $95.21 \%$, followed by BHA $(94.82 \%)$, BHT $(93.92 \%)$ and OMC (8.99\%) (Figure 1).

The percentage can be considered as total scavenging of $\mathrm{DPPH}^{*}$ radicals because after the reaction complete, a final solution showed a yellow color. A purple $\mathrm{DPPH}^{*}$ radical when received a hydrogen atom from phenolic antioxidants is converted to yellow non-radical, DPPH-H (Katalinic et al. 2006).

Figure 1 shows BHA and BHT are easily donate hydrogen atom to free radicals ( $\mathrm{DPPH} \bullet$ ). Whereas, $\mathrm{OMC}$ is difficult to donate a hydrogen atom since methoxy group (-OCH3) has higher redox potential than hydroxyl group (-OH) (Ozgen et al. 2006). The $\mathrm{IC}_{50}$ of BHA, BHT and mixture were 29.83, 44.16, $32.51 \mathrm{mg} / \mathrm{L}$, respectively. The DPPH inhibition for control sample was $2.63 \%$. The percentage of DPPH inhibition for BHA, BHT, OMC and mixture at six level of concentration are presented in Table 1.

By comparing the results in Tables 1 and 2, it was observed that the scavenging activities (DPPH inhibition \%) of phenolic compounds in personal care products were lower than standard phenolic compounds under similar analytical condition. The results can be wrongly interpreted if the personal care products contain trace of metal ions. The metal ions can be chelated with BHA, BHT and EDTA (Geckil et al. 2005). Thus, the number of hydrogen atoms donated is less, while DPPH radical is unaffected by the presence of metal ions, chelate agents and enzyme inhibition (Amarowicz et al. 2004; Sawant et al. 2009).

\section{Antibacterial Activity}

Mixture sample showed the highest antibacterial activity compared to BHA, BHT and OMC since the inhibition zone diameter for a mixture sample was bigger than the inhibition zone diameters for BHA, BHT and OMC at the same concentration (Tables $3 \& 4$ ).

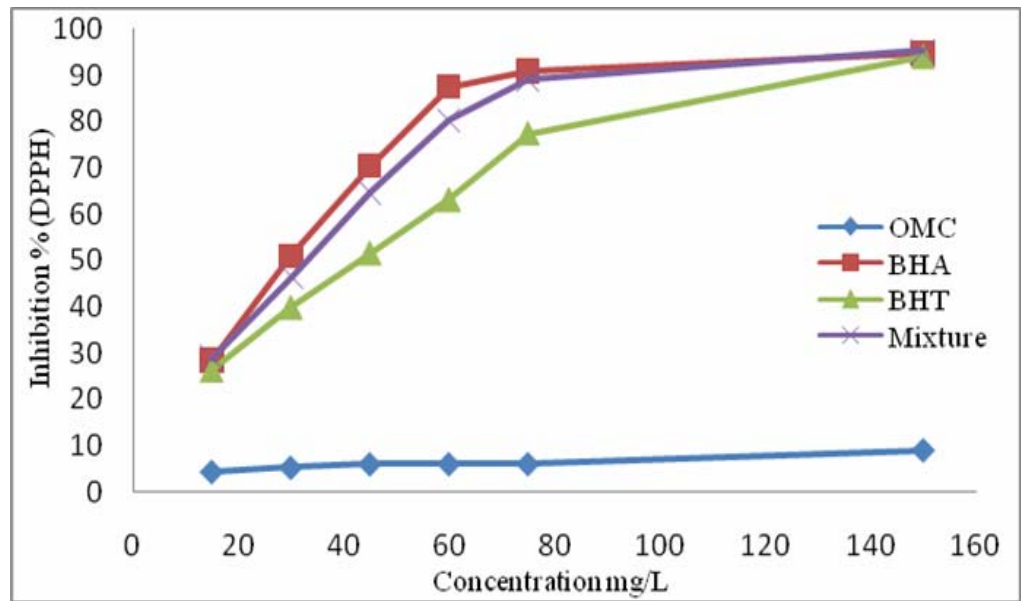

Figure 1. Percentage of $\mathrm{DPPH}^{\bullet}$ inhibition for $\mathrm{BHA}, \mathrm{BHT}, \mathrm{OMC}$ and mixture monitored by UV/Vis spectrophotometer at $\lambda_{\max }=517 \mathrm{~nm}$. 
Table 1. Kinetic of DPPH inhibition (\%) for BHA, BHT, OMC and mixture during 30 minutes by UV/Visspectrophotometer at $\lambda_{\max }=517 \mathrm{~nm},($ mean $\pm \mathrm{SD}, \mathrm{n}=3)$

\begin{tabular}{|c|c|c|c|c|c|c|c|}
\hline \multirow{2}{*}{\multicolumn{2}{|c|}{$\begin{array}{l}\text { Concentration } \\
(\mathrm{mg} / \mathrm{l})\end{array}$}} & \multicolumn{6}{|c|}{ Inhibition of DPPH \% } \\
\hline & & $5 \mathrm{~min}$ & $10 \mathrm{~min}$ & $15 \mathrm{~min}$ & $20 \mathrm{~min}$ & $25 \mathrm{~min}$ & $30 \mathrm{~min}$ \\
\hline \multirow{6}{*}{ BHA } & 15 & $10.1 \pm 0.1$ & $12.5 \pm 0.1$ & $14.4 \pm 0.1$ & $17.2 \pm 0.1$ & $20.2 \pm 0.1$ & $28.5 \pm 0.1$ \\
\hline & 30 & $22.5 \pm 0.2$ & $32.1 \pm 0.1$ & $38.0 \pm 0.1$ & $42.6 \pm 0.1$ & $48.6 \pm 0.1$ & $51.0 \pm 0.1$ \\
\hline & 45 & $31.7 \pm 0.2$ & $39.6 \pm 0.2$ & $46.2 \pm 0.1$ & $53.5 \pm 0.1$ & $62.4 \pm 0.1$ & $70.5 \pm 0.1$ \\
\hline & 60 & $67.5 \pm 0.3$ & $39.6 \pm 0.1$ & $46.2 \pm 0.1$ & $53.6 \pm 0.1$ & $62.4 \pm 0.0$ & $87.6 \pm 0.0$ \\
\hline & 75 & $69.9 \pm 0.3$ & $79.5 \pm 0.2$ & $85.1 \pm 0.1$ & $87.6 \pm 0.1$ & $89.6 \pm 0.0$ & $90.8 \pm 0.0$ \\
\hline & 150 & $88.5 \pm 0.4$ & $91.4 \pm 0.1$ & $93.3 \pm 0.1$ & $94.3 \pm 0.0$ & $94.9 \pm 0.0$ & $94.8 \pm 0.0$ \\
\hline \multirow{6}{*}{ BHT } & 15 & $13.2 \pm 0.2$ & $16.5 \pm 0.1$ & $19.2 \pm 0.1$ & $21.9 \pm 0.1$ & $24.6 \pm 0.1$ & $26.2 \pm 0.1$ \\
\hline & 30 & $16.3 \pm 0.2$ & $24.6 \pm 0.2$ & $29.1 \pm 0.1$ & $34.0 \pm 0.1$ & $36.5 \pm 0.1$ & $39.8 \pm 0.1$ \\
\hline & 45 & $24.0 \pm 0.3$ & $32.9 \pm 0.2$ & $39.0 \pm 0.1$ & $44.3 \pm 0.1$ & $48.4 \pm 0.1$ & $51.5 \pm 0.1$ \\
\hline & 60 & $19.4 \pm 0.3$ & $40.5 \pm 0.1$ & $47.9 \pm 0.1$ & $54.3 \pm 0.1$ & $59.3 \pm 0.1$ & $63.1 \pm 0.1$ \\
\hline & 75 & $44.9 \pm 0.3$ & $57.9 \pm 0.2$ & $66.6 \pm 0.1$ & $70.5 \pm 0.1$ & $74.5 \pm 0.0$ & $77.3 \pm 0.1$ \\
\hline & 150 & $81.8 \pm 0.3$ & $87.6 \pm 0.1$ & $91.1 \pm 0.0$ & $92.3 \pm 0.0$ & $93.9 \pm 0.0$ & $93.9 \pm 0.0$ \\
\hline \multirow{6}{*}{ OMC } & 15 & $2.6 \pm 0.1$ & $3.1 \pm 0.0$ & $3.4 \pm 0.0$ & $3.9 \pm 0.0$ & $4.1 \pm 0.0$ & $4.3 \pm 0.0$ \\
\hline & 30 & $4.2 \pm 0.0$ & $4.4 \pm 0.0$ & $4.6 \pm 0.0$ & $4.9 \pm 0.0$ & $5.1 \pm 0.0$ & $5.2 \pm 0.0$ \\
\hline & 45 & $4.1 \pm 0.0$ & $4.5 \pm 0.0$ & $4.9 \pm 0.0$ & $5.1 \pm 0.0$ & $5.9 \pm 0.0$ & $6.0 \pm 0.0$ \\
\hline & 60 & $4.9 \pm 0.0$ & $5.2 \pm 0.0$ & $5.4 \pm 0.0$ & $5.6 \pm 0.0$ & $5.8 \pm 0.0$ & $6.1 \pm 0.0$ \\
\hline & 75 & $5.1 \pm 0.0$ & $5.2 \pm 0.0$ & $5.5 \pm 0.0$ & $5.8 \pm 0.0$ & $5.9 \pm 0.0$ & $6.1 \pm 0.0$ \\
\hline & 150 & $7.9 \pm 0.0$ & $8.2 \pm 0.0$ & $8.4 \pm 0.0$ & $8.7 \pm 0.0$ & $8.8 \pm 0.0$ & $9.0 \pm 0.0$ \\
\hline \multirow{6}{*}{ Mixture } & 15 & $9.4 \pm 0.1$ & $15.9 \pm 0.1$ & $20.2 \pm 0.1$ & $23.4 \pm 0.1$ & $26.5 \pm 0.1$ & $28.9 \pm 0.1$ \\
\hline & 30 & $12.7 \pm 0.2$ & $18.6 \pm 0.2$ & $28.8 \pm 0.1$ & $36.8 \pm 0.1$ & $42.0 \pm 0.1$ & $46.4 \pm 0.1$ \\
\hline & 45 & $25.4 \pm 0.4$ & $36.3 \pm 0.2$ & $44.0 \pm 0.1$ & $49.2 \pm 0.1$ & $57.4 \pm 0.1$ & $64.8 \pm 0.1$ \\
\hline & 60 & $32.9 \pm 0.4$ & $47.1 \pm 0.2$ & $56.8 \pm 0.1$ & $70.2 \pm 0.1$ & $76.6 \pm 0.1$ & $80.3 \pm 0.1$ \\
\hline & 75 & $50.8 \pm 0.4$ & $66.9 \pm 0.2$ & $76.2 \pm 0.1$ & $82.0 \pm 0.1$ & $86.0 \pm 0.1$ & $89.1 \pm 0.1$ \\
\hline & 150 & $82.1 \pm 0.2$ & $89.9 \pm 0.1$ & $91.9 \pm 0.1$ & $92.9 \pm 0.1$ & $94.3 \pm 0.0$ & $95.2 \pm 0.0$ \\
\hline
\end{tabular}

Table 2. Kinetic of DPPH inhibition (\%) for crude extract of selected personal care products during 30 minutes by UV/Vis spectrophotometer at $\lambda_{\max }=517 \mathrm{~nm},($ mean $\pm \mathrm{SD}, \mathrm{n}=3)$

\begin{tabular}{lccccccc}
\hline $\begin{array}{l}\text { Product } \\
\text { (commercial } \\
\text { brand) }\end{array}$ & Amount & $5 \mathrm{~min}$ & $10 \mathrm{~min}$ & $15 \mathrm{~min}$ & $20 \mathrm{~min}$ & $25 \mathrm{~min}$ & $30 \mathrm{~min}$ \\
\cline { 3 - 8 } $\begin{array}{l}\text { Sunscreen cream } \\
\text { (Aiken) }\end{array}$ & $0.342 \mathrm{~g}$ & $6.0 \pm 0.2$ & $8.3 \pm 0.1$ & $10.1 \pm 0.1$ & $11.7 \pm 0.1$ & $12.7 \pm 0.1$ & $14.0 \pm 0.0$ \\
& $0.407 \mathrm{~g}$ & $8.5 \pm 0.2$ & $9.3 \pm 0.1$ & $10.2 \pm 0.1$ & $11.1 \pm 0.1$ & $11.9 \pm 0.1$ & $12.8 \pm 0.1$ \\
& $0.479 \mathrm{~g}$ & $11.0 \pm 0.2$ & $12.0 \pm 0.2$ & $12.7 \pm 0.1$ & $13.7 \pm 0.1$ & $14.7 \pm 0.1$ & $15.3 \pm 0.1$ \\
\hline Milk lotion & $0.487 \mathrm{~g}$ & $11.7 \pm 0.3$ & $12.5 \pm 0.1$ & $13.5 \pm 0.1$ & $14.2 \pm 0.1$ & $15.2 \pm 0.0$ & $16.0 \pm 0.0$ \\
(Nivea) & $0.901 \mathrm{~g}$ & $16.2 \pm 0.3$ & $18.0 \pm 0.2$ & $19.5 \pm 0.1$ & $21.0 \pm 0.1$ & $22.0 \pm 0.0$ & $23.5 \pm 0.0$ \\
& $0.320 \mathrm{~g}$ & $12.0 \pm 0.4$ & $13.5 \pm 0.1$ & $15.0 \pm 0.1$ & $16.2 \pm 0.0$ & $17.5 \pm 0.0$ & $18.7 \pm 0.0$ \\
\hline Hair gel & $0.426 \mathrm{~g}$ & $5.8 \pm 0.2$ & $6.1 \pm 0.1$ & $6.4 \pm 0.1$ & $6.7 \pm 0.1$ & $6.9 \pm 0.0$ & $7.2 \pm 0.0$ \\
(De Boy) & $0.558 \mathrm{~g}$ & $3.9 \pm 0.2$ & $4.2 \pm 0.2$ & $4.6 \pm 0.1$ & $4.9 \pm 0.1$ & $5.11 \pm 0.1$ & $5.3 \pm 0.0$ \\
& $0.454 \mathrm{~g}$ & $5.6 \pm 0.3$ & $6.1 \pm 0.2$ & $6.5 \pm 0.1$ & $6.9 \pm 0.1$ & $7.3 \pm 0.1$ & $7.7 \pm 0.0$ \\
\hline Hair oil & $0.5 \mathrm{~mL}$ & $6.4 \pm 0.3$ & $7.8 \pm 0.1$ & $8.9 \pm 0.1$ & $10.2 \pm 0.1$ & $11.5 \pm 0.1$ & $12.7 \pm 0.1$ \\
(Elite) & $1.0 \mathrm{~mL}$ & $4.9 \pm 0.3$ & $5.7 \pm 0.2$ & $6.7 \pm 0.1$ & $7.9 \pm 0.1$ & $8.7 \pm 0.1$ & $10.1 \pm 0.1$ \\
& $1.5 \mathrm{~mL}$ & $5.6 \pm 0.3$ & $7.0 \pm 0.1$ & $8.1 \pm 0.0$ & $9.7 \pm 0.0$ & $11.3 \pm 0.0$ & $12.6 \pm 0.0$ \\
\hline
\end{tabular}


Tables 3 and 4 showed that E. coli was more susceptible than $S$. aureus when treated with BHA, BHT, OMC and mixture at the similar condition with those reported in literature (Chew et al. 1985; Collins \& Charles, 1987; Nakazono et al. 2006). Paper-disk diffusion technique was found to be more sensitive than hole-punch technique for antibacterial activity evaluation which is similar finding with those reported by other researchers (Tseng \& Tseng 1995; Lee 2000; Nakazono et al. 2006). Antibacterial activities of BHA and BHT were consistent with those reported by other researchers (Kabara 1980; Chew et al. 1985; Lee 2000; Romano et al. 2009) which stated that BHA is more active than BHT against $E$. coli and $S$. aureus.

Table 3. Comparison of inhibition zone diameters for BHA, BHT, OMC and mixture (mean $\pm \mathrm{SD}, \mathrm{n}=3$ ) against Staphylococcus aureus by agar plate diffusion method

\begin{tabular}{ccccc|cccc}
\hline \multirow{2}{*}{$\begin{array}{c}\text { Concentration } \\
(\mu \mathrm{g} / \text { disk or } \\
\text { hole })\end{array}$} & \multicolumn{7}{c}{ Inhibition zone diameter $(\mathrm{mm})$} \\
\cline { 2 - 10 } & BHA & BHT & OMC & mixture & BHA & BHT & OMC & mixture \\
\cline { 2 - 10 } & $19.0 \pm 1.0$ & $14.0 \pm 0.0$ & n.a & $27.0 \pm 1.7$ & $15.0 \pm 0.0$ & $12.3 \pm 0.6$ & n.a & $18.0 \pm 1.0$ \\
400 & $17.3 \pm 0.6$ & $12.0 \pm 0.0$ & n.a & $26.0 \pm 1.0$ & $14.3 \pm 0.6$ & $10.0 \pm 0.0$ & n.a & $16.3 \pm 0.6$ \\
200 & $15.3 \pm 0.6$ & $10.0 \pm 0.0$ & n.a & $25.0 \pm 1.0$ & $12.0 \pm 0.0$ & n.a & n.a & $13.0 \pm 0.0$ \\
120 & $12.3 \pm 0.6$ & $8.0 \pm 0.0$ & n.a & $23.0 \pm 1.0$ & $10.0 \pm 0.0$ & n.a & n.a & $11.0 \pm 0.0$ \\
70 & $8.0 \pm 0.0$ & n.a & n.a & $10.0 \pm 0.0$ & n.a & n.a & n.a & n.a \\
15 & n.a & n.a & n.a & $8.0 \pm 0.0$ & n.a & n.a & n.a & n.a \\
10 & n.a & n.a & n.a & n.a & n.a & n.a & n.a & n.a \\
1.5 & & & & & & & &
\end{tabular}

Note: n.a (not active).

Table 4. Comparison of inhibition zone diameters for $\mathrm{BHA}, \mathrm{BHT}, \mathrm{OMC}$ and mixture (mean $\pm \mathrm{SD}, \mathrm{n}=3$ ) against $E$. coli by agar plate diffusion method

\begin{tabular}{ccccc|cccc}
\hline \multirow{2}{*}{$\begin{array}{l}\text { Concentration } \\
(\mu \mathrm{g} / \text { disk or }\end{array}$} & \multicolumn{7}{c}{ Inhibition zone diameter $(\mathrm{mm})$} \\
\cline { 2 - 9 } hole $)$ & BHA & BHT & OMC & mixture & BHA & BHT & OMC & mixture \\
\hline & $26.7 \pm 2.1$ & $15.7 \pm 1.5$ & $11.0 \pm 0.0$ & $30.0 \pm 2.6$ & $16.0 \pm 0.0$ & $12.0 \pm 0.6$ & n.a & $19.3 \pm 1.5$ \\
\hline 400 & $24.7 \pm 1.5$ & $14.0 \pm 1.0$ & $10.0 \pm 0.0$ & $28.3 \pm 1.1$ & $14.0 \pm 0.0$ & $10.0 \pm 0.0$ & n.a & $17.0 \pm 1.0$ \\
200 & $16.0 \pm 0.0$ & $12.3 \pm 0.6$ & n.a & $24.3 \pm 1.5$ & $11.0 \pm 0.0$ & n.a & n.a & $12.0 \pm 0.0$ \\
120 & $14.0 \pm 0.0$ & $10.0 \pm 0$ & n.a & $22.0 \pm 1.0$ & n.a & n.a & n.a & $10.0 \pm 0.0$ \\
70 & $12.3 \pm 0.6$ & $8.0 \pm 0$ & n.a & $16.0 \pm 1.0$ & n.a & n.a & n.a & n.a \\
15 & $10.0 \pm 0.0$ & n.a & n.a & $9.3 \pm 0.6$ & n.a & n.a & n.a & n.a \\
10 & $8.0 \pm 0.0$ & n.a & n.a & $8.0 \pm 0.0$ & n.a & n.a & n.a & n.a \\
1.5 & & & & & & & &
\end{tabular}

Note: n.a (not active). 
Table 5. The MIC values for BHA, BHT, OMC and mixture determine by two paper-disk diffusion and hole-punch diffusion techniques

\begin{tabular}{|c|c|c|c|c|}
\hline \multirow{3}{*}{ Phenolic compound } & \multicolumn{4}{|c|}{ MIC ( $\mu \mathrm{g} /$ disk or hole $)$} \\
\hline & \multicolumn{2}{|c|}{$\begin{array}{c}\text { S. aureus } \\
\text { (ATCC 29213) }\end{array}$} & \multicolumn{2}{|c|}{$\begin{array}{c}\text { E. coli } \\
\text { (ATCC 25922) }\end{array}$} \\
\hline & disk-diffusion & hole-diffusion & disk-diffusion & hole-diffusion \\
\hline BHA & 15 & 1.5 & 10 & 15 \\
\hline BHT & 70 & 15 & 200 & 70 \\
\hline $\mathrm{OMC}$ & n.a & 200 & n.a & n.a \\
\hline Mixture & 10 & 1.5 & 70 & 10 \\
\hline
\end{tabular}

Note: n.a (not active).

The MIC values were the lowest concentrations of BHA, BHT, OMC and mixture that give the lowest visible inhibition-zone (Tseng \& Tseng 1995). The MIC values for analytes studied are presented in Table 5.

Mixture of BHA, BHT and OMC has the highest antibacterial activity based on MIC values (see Table 5; Figures $2 \& 3$ ). The MIC values for BHA, BHT, OMC and mixture against $E$. coli using paper-disk diffusion technique were 1.5, 15, 200, $1.5 \mu \mathrm{g} /$ disk, respectively. While, the MIC values obtained using hole-punch technique were 100, 200, n.a, $70 \mu \mathrm{g} /$ hole, respectively. In addition, the MIC values for BHA, BHT, OMC and mixture against
S. aureus using paper-disk diffusion technique were 15,70 , n.a, $10 \mu \mathrm{g} /$ disk, respectively. Whereas, the MIC values obtained using hole-punch technique were 70,200 , n.a and $60 \mu \mathrm{g}$ /hole, respectively. These MIC values are lower compared with MIC values reported by Kabara (1980).

The antibacterial activities for extract of selected personal care samples are presented in Tables 6 and 7 against $S$. aureus and E. coli using paper-disk and hole-punch diffusion techniques.

Generally, the antibacterial activities for extract from selected cosmetic samples against $S$. aureus and $E$. coli were higher than the antibacterial activity of standard phenolic compounds at similar analytical conditions.

Table 6. Inhibition zone diameter for extract of selected personal care samples (mean $\pm \mathrm{SD}, \mathrm{n}=3$ ) against $S$. aureus by agar plate diffusion method

\begin{tabular}{lccc}
\hline \multicolumn{1}{c}{$\begin{array}{c}\text { Sample } \\
\text { (Commercial brand })\end{array}$} & $\begin{array}{c}\text { Weight } \\
(\mathrm{g})\end{array}$ & \multicolumn{2}{c}{ Inhibition zone diameter $(\mathrm{mm})$} \\
\cline { 3 - 4 } Snscreen cream & 0.312 & $14.0 \pm 0.6$ & hole-punch diffusion \\
(Aiken) & 1.123 & $19.3 \pm 1.5$ & n.a \\
& 2.688 & $26.7 \pm 0.6$ & $12.0 \pm 0.0$ \\
Milk lotion & 0.397 & $16.0 \pm 1.0$ & n.a \\
(NIVEA) & 1.282 & $22.0 \pm 1.0$ & $12.0 \pm 0.0$ \\
& 2.816 & $30.0 \pm 2.6$ & $14.0 \pm 0.0$ \\
Hair gel & 1.065 & $8.0 \pm 0.0$ & n.a \\
(DE BOY) & 3.341 & $11.0 \pm 0.0$ & n.a \\
& 4.984 & $14.0 \pm 0.0$ & n.a \\
Hair oil & 0.300 & $12.0 \pm 1.0$ & n.a \\
(Elite) & 1.250 & $16.0 \pm 1.0$ & n.a \\
& 3.750 & $19.3 \pm 1.5$ & n.a \\
\hline
\end{tabular}

Note : n.a: not active. 
Table 7. Inhibition zone diameter for crude extract of selected personal care samples ( $m e a n \pm S D, n=3$ ) against $E$. coli by agar plate diffusion method

\begin{tabular}{lccc}
\hline \multirow{2}{*}{$\begin{array}{c}\text { Sample } \\
\text { (Commercial brand })\end{array}$} & $\begin{array}{c}\text { Weight } \\
(\mathrm{g})\end{array}$ & \multicolumn{2}{c}{ Inhibition zone diameter $(\mathrm{mm})$} \\
\cline { 3 - 4 } Sunscreen cream & 0.312 & paper-disk diffusion & hole-punch diffusion \\
(Aiken) & 1.123 & $12.3 \pm 0.6$ & n.a \\
& 2.688 & $17.0 \pm 1.0$ & $10.0 \pm 0.0$ \\
Milk lotion & 0.397 & $24.3 \pm 1.5$ & n.a \\
(NIVEA) & 1.282 & $15.7 \pm 1.5$ & $10.0 \pm 0.0$ \\
& 2.816 & $20.7 \pm 1.1$ & $12.0 \pm 0.0$ \\
Hair gel & 1.065 & $28.3 \pm 1.1$ & n.a \\
(DE BOY) & 3.341 & $8.0 \pm 0.0$ & n.a \\
& 4.984 & $10.0 \pm 0.0$ & n.a \\
Hair oil & 0.400 & $12.3 \pm 0.6$ & n.a \\
(Elite) & 1.250 & $14.0 \pm 1.0$ & n.a \\
& 3.250 & $17.0 \pm 1.0$ & $10.0 \pm 0.0$
\end{tabular}

Note : n.a: not active.

The enhance antibacterial activities probably due to antimicrobial agents such as methylparaben, ethylparaben, propylparaben and butylparaben (Davin-Regli et al., 2006; Chen et al., 2007). In addition, $S$. aureus was more susceptible than $E$. coli when treated with extract of selected cosmetic samples (see Figures $4 \& 5$ ) and this is similar to those reported by Kabara (1980). On other hand, E. coli was more susceptible than $S$. aureus when treated with BHA, BHT, OMC and mixture. The weight of real samples was almost commensurate with the amount of BHA in the label of these personal care products since BHA is higher antibacterial antioxidant activities than BHT and OMC.

\section{CONCLUSION}

The antioxidant and antibacterial activities for BHA, $\mathrm{BHT}, \mathrm{OMC}$ and mixture showed the significant activities by inhibition DPPH and growth of bacteria can be arranged with the following order : mixture $>$ $\mathrm{BHA}>\mathrm{BHT}>\mathrm{OMC}$. The antioxidant and antibacterial activities of these phenolic compounds depend on degree of steric hindrance and number of hydroxyl group.

The extract of selected personal care products were capable to to inhibit the growth of $E$. coli and $S$. aureus than $\mathrm{BHA}, \mathrm{BHT}, \mathrm{OMC}$ and mixture since personal care formulations contain antimicrobial agents. Thus, milk lotion is more active against $E$. coli and $S$. aureus than other personal care products studied. Furthermore, paper-disk diffusion is more sensitive technique than hole-punch for determination of antibacterial activities of BHA, BHT, OMC, mixture and extract of selected personal care products. The MIC values of these phenolic compounds were higher against $S$. aureus $(10-200 \mu \mathrm{g} /$ disk or hole) than E. coli $(1.5-200$ $\mu \mathrm{g} /$ disk or hole).

\section{ACKNOWLEDGEMENTS}

The authors wish to thank Syrian Ministry of Higher Education for a scholarship given to Mohd Akkbik and Department of Chemistry, Faculty of Resource Science and Technology, UNIMAS for research facilities for this study.

\section{REFERENCES}

Abdoul-Latif, F., Edou, P., Eba, F., Mohamed, N., Ali, A., Djama, S., Obame, L.C., Bassole, I. \& Dicko, M. (2010). Antimicrobial and antioxidant activities of essential oil and methanol extract of Jasminum sambac from Djibouti. African Journal of Plant Science, 4: 38-43. 
Amarowicz, R., Pegg, R.B., Rahimi-Moghaddam, P., Barl, B. \& Weil, J.A. (2004). Free radical scavenging capacity and antioxidant activity of selected plant species from the Canadian prairies. Food Chemistry, 84: 551-62.

Apostolova, E.G.K., Georgiev, M.I., Ilieva, M.P., Skibsted, L.H., Rodtjer, A. \& Andersen, M.L. (2008). Extracts of plant cell cultures of Lavandula vera and Rosa damascena as sources of phenolic antioxidants for use in foods. European Food Research Technology, 227: 1243-1249.

Brand-Williams, W., Cuvelier, M.E. \& Berset, C. (1995). Use of a free radical method to evaluate antioxidant activity. Lebensmittel Wissenschaft and Technology, 28: 25-30.

Chen, J., Ahn, K.C., Gee, N.A., Gee, S. J., Hammock, B.D. \& Lasley, B.L. (2007). Antiandrogenic properties of parabens and other phenolic containing small molecules in personal care products. Toxicology and Applied Pharmacology, 221:278-284.

Chew, B.P., Tjoelker, L.W. \& Tanaka, T.S. (1985). In vitro growth inhibition of mastitis causing bacteria by phenolics and metal chelators. Journal of Dairy Science, 68: 3037-3046.

Chryssanthou, E. \& Cuenca-Estrella, M. (2006). Comparison of the EUCAST-AFST broth dilution method with the CLSI reference broth dilution method (M38-A) for susceptibility testing of posaconazole and voriconazole against Aspergillus spp. Clinical Microbiology and Infection, 12: 901-904.

Collins, M.A. \& Charles, H.P. (1987). Antimicrobial activity of Carnosol and Ursolic acid: Two antioxidant constituents of Rosmarinus officinalis L. Food Microbiology, 4: 311-315.

Davin-Regli, A., Chollet, R., Bredin, J., Chevalier, J., Lepine, F. \& Pages, J.M. (2006). Enterobacter gergoviae and the prevalence of efflux in parabens resistance. Journal of Antimicrobial Chemotherapy, 57: 757-760.

Gaudreau, C., Girouard, Y., Gilbert, H., Gagnon, J. $\&$ Bekal, S. (2008). Comparison of disk diffusion and agar dilution methods for erythromycin, ciprofloxacin, and tetracycline susceptibility testing of campylobacter coli and for tetracycline susceptibility testing of campylobacter jejuni subsp. Antimicrobial Agents and Chemotherapy, 52: 4475-4477.
Geckil, H., Ates, B., Durmaz, G., Erdogan, S. \& Yilmaz, I. (2005). Antioxidant, free radical scavenging and metal chelating characteristics of propolis. American Journal of Biochemistry and Biotechnology, 1: 27-31.

Gulcin, I., Elias, R., Akcahan, A., Gepdiremen, A., Taoubi, K. \& Koksal, E. (2009). Antioxidant secoiridoids from fringe tree. Wood Science Technology, 43: 195-212.

Kabara, J.J. (1980). GRAS antimicrobial agents for cosmetic products. Journal of the Society of Chemists, 31: 1-10.

Katalinic, V., Milos, M., Kulisic, T. \& Jukic, M. (2006). Screening of 70 medicinal plant extracts for antioxidant capacity and total phenols. Food Chemistry, 94: 550-557.

Klich, M.A., Tang, S. \& Denning, D.W. (2009). Aflatoxin and ochratoxin production by aspergillus species under ex-vivo conditions. Mycopathologia, 168, 185-191.

Lee, S.K. (2000). Antimicrobial activity of Bamboo (Phyllostachys bambusoides) essential oil. Journal of Food Hygiene and Safety, 15: 55-59.

Lee, G.S., Widjaja, A. \& Ju, Y.H. (2006). Enzymatic synthesis of cinnamic acid derivatives. Biotechnology Letters, 28: 581-585.

Mandal, P., Misra, T.K. \& Ghosal, M. (2009). Free radical scavenging activity and phytochemical analysis in the leaf and stem. International Journal of Integrative Biology, 7: 80 - 84.

Nakazono, Y., Watanbe, Y., Hashinaga, F. \& Tedera, K. (2006). Studies on antimicrobial and antioxidative substance of Yuzu (Citrus junos hort ex Tanaka) seed. Journal of Biological Sciences, 6: 135-139.

Osman Y.A.H., Yaseen, E.M. \& Farag, M.M. (2009). Antimicrobial effect of some essential oils mixtures. Journal of Applied Sciences Research, 5(9): 1265-1276.

Ozgen, M., Reese, R.N., Tuliojr, A.Z., Scheerens, J.C. \& Miller, A.R. (2006). Modified 2,2-azino-bis-3-ethylbenzothiazoline-6-sulfonic acid (ABTS) method to measure antioxidant capacity of selected small fruits and comparison to ferric reducing antioxidant power (FRAP) and 2,2'-diphenyl-1-picrylhydrazyl (DPPH) methods. Journal of Agricultural and Food Chemistry, 54: 1151-1157. 
Peschel, W., Ferran, S.R., Wilfried, D., Andreas, P., Irene, G. \& Diego, J. (2006). An industrial approach in the search of natural antioxidants from vegetable and fruit wastes. Food Chemistry, 97: 137-150.

Post, L.S. \& Davidson, P.M. (1986). Lethal effect of butylated hydroxyanisole as related to bacterial fatty acid composition. Applied and Environmental Microbiology, 52: 214-216.

Romano, C.S., Abadi, K., Repetto, V., Vojnov, A.A. \& Moreno, S. (2009). Synergistic antioxidant and antibacterial activity of rosemary plus butylated derivatives. Food Chemistry, 115: 456-461.

Sawant, O., Kadam, V.J. \& Ghosh, R. (2009). In vitro free radical scavenging and antioxidant activity of Adiantum Lunulatum. Journal of Herbal Medicine and Toxicology, 3: 39-44.

Simonetti, G., Simonetti, N. \& Villa, A. (2003). Increase of activity of tioconazole against resistant microorganisms by the addition of butylated hydroxyanisole. International Journal of Antimicrobial Agents, 22: 439-443.
Singh, G., Kapoor, I.P.S., Singh, P., De-Heluani, C.S., De-Lampasona, M.P. \& Catalan, C.A.N. (2008). Chemistry, antioxidant and antimicrobial investigations on essential oil and oleoresins of Zingiber officinale. Food and Chemical Toxicology, 46: 3295-3302.

Thaiponga, K., Boonprakoba, U., Crosbyb, K., Zevallose, L.C. \& Byrne, D.H. (2006). Comparison of ABTS, DPPH, FRAP, and ORAC assays for estimating antioxidant activity from guava fruit extracts. Journal of Food Composition and Analysis, 19: 669-675.

Tseng, H.H. \& Tseng, T.C. (1995). Effects of butylated hydroxyanisole, butylated hydroxytoluene and tertiary butylhydroquinone on growth and luteoskyrin production by Penicillium islandicum. Mycopathologia, 129: 73-78. 